\title{
Amplitude Adaptive Notch Filter With Optimized PI Gains for Mitigation of Voltage Based Power Quality Problems
}

\author{
Sabha Raj Arya, Rakesh Maurya, and Talada Appala Naidu
}

\begin{abstract}
In this paper, a three wire DVR has been implemented using control algorithm based on amplitude adaptive notch filter for mitigation of voltage based power quality problems. The compensation of voltage sag, voltage swell, distortions, and imbalance imposed in the supply voltage due to various reasons is carried out using this series connected devices. The amplitude adaptive notch filter (AANF) offers advantages in extracting components like frequency, angle, and sequence components with very simple and fast responding synchronization scheme. It does not require any phase locked loop (PLL) for estimating phase angle or frequency of input signals. The fundamental positive sequence components (FPSCs) embedded in the measured signals is separated using the control algorithm and then utilized in estimation of three phase reference load voltage. The optimization approach for tuning the PI controller's gains is proposed in the developed control algorithm. That is nature inspired whale optimization algorithm (WOA) has been used due to its competitiveness compared to conventional optimization algorithm. The WOA provides the appropriate values of proportional integration (PI) controller's gains within less time as compared to manual tuning of PI controller. The simulation and test performance are discussed to validate the proposed control algorithm in non-ideal AC mains.
\end{abstract}

Index terms - DVR, fundamental positive sequence components (FPSC), harmonics, imbalance, optimization, sag and swell.

\section{INTRODUCTION}

$\mathrm{D}$ UE to the widespread usage of power electronic devices in the power system, the importance of power quality has increased rapidly [1]. The reliability of the power system at the particular load center depends upon the interconnection of a large number of sources. The idea of custom power devices (CPDs) has been introduced in the distribution system to mitigate power quality issues [2]. Power quality issues related to voltage variations creating appreciable effects on both the generation and different types of loads. A Dynamic Voltage Restorer has been introduced in the distribution system to overcome these voltage related power quality issues [3]. The

Manuscript received April 18, 2018. This work was supported by Science and Engineering Research Board-New Delhi Research Project under Extra Mural Research Funding Scheme under Grant No. SB/S3/EECE/030/2016, Dated 17/08/2016.

The authors are with the Department of Electrical Engineering, Sardar Vallabhbhai National Institute of Technology, Surat 395007, India (e-mail: sabharaj79@gmail.com; rmaurya@eed.svnit.ac.in; naidu284@gmail.com).

Digital Object Identifier 10.24295/CPSSTPEA.2018.00031 standard levels for the voltage harmonics need to be maintained have been reported in IEEE Std. [4].

DVR is the series injecting voltage source converter (VSC) based CPD which has been used for compensating the voltage related power quality issues. Mahdianpoor et al. in [5] have proposed a multifunctional DVR with a closed-loop controller with Posicast and Proportional plus resonant controllers to improve the transient response of the controller. Authors in [6], have proposed a least error squared based control algorithm for DVR and the DVR with this control is effectively compensating all the sequence components of load voltage with zero steadystate error. Sanchez et al. in [7] designed a repetitive control based closed-loop for a 2-level DVR for compensating power quality issues like voltage sags, harmonics, and imbalances in the voltage. Wessels et al. in [8] has investigated the application of a DVR connected to a wind turbine DFIG to allow noninterruptible fault ride through of grid voltage faults. A new hybrid DVR system topology is developed experimentally, in which a method of interfacing superconducting magnetic energy storage and BESS has been investigated to support a three-phase load [9].

Nielsen et al. in [10] have been tested at medium voltage level DVR with software-based PLL for creating reference load voltage for controlling DVR. Zhan et al. in [11], have considered the design issues of three-phase DVR and SPLL under voltage unbalance, voltage harmonics, frequency change, and phase jumps. Enhancement in the PLLs from the standard PLL with advantages like estimation of useful signals those help in the control of power engineering application [12]. Eren et al. in [13] have proposed the combination of conventional SRFPLL and ANF for error due to harmonics and unbalances in the signal. PLLs used for extraction of information embedded in the distorted signals like amplitude, frequency/phase angle, fundamental components have been suffering in the accuracy and computational complexity due to number of pre-filter based control algorithms. Due to these reasons, a new approach of amplitude adaptive filters have been presented to estimate unknown parameters embedded in any disturbed sinusoidal signals without using any PLLs in literature [14]-[17].

Authors in text [14], have introduced two algorithms, direct and indirect adaptive algorithms for estimating the unknown frequency from the distorted sinusoidal signal. Yazdani et al. in [15], have been introduced a new 3-phase amplitude adaptive notch filter for online extraction of the fundamental magnitude 
and frequency/phase angle of any given disturbed waveform. This method of synchronization does not require any phase locked loops. Authors in [16], have discussed both the grid connected and the stand alone mode of micro grids with AANF as a tool for grid signal processing and distributed system synchronization. Shitole et al. [17], has been developed a three phase AANF based modified current control loop for real time estimation of supply voltage frequency and phase angle to generate the reference current for synchronization of interfacing inverter. It has been observed that AANF has several advantages with respect to control algorithm for DVR such as estimation of magnitude, frequency or phase, fundamental and its quadrature components, and sequential components of a given distorted signal. In this algorithm, PLLs and any transformations like Clark's or Park's are not required. Thus need less computational burden during real time processing. Even though, there are available methods of automatic PI controller tuning, it has been more practice of tuning a PI controller manually (i.e. trial and error) because of the ineffective solution with automatic tuning methods [18]. However, the manual tuning method consumes considerable time and tends to decrease the speed control algorithm implementation. Approach of the optimization techniques has been introduced in the PI controllers design for fast and accurate PI gains estimation [19]. The error of actual and reference signals are modeled as one of the performance indices for defining the cost function. The idea of optimization technique has been adopted in the PI gains estimation for DVR control in [20]. A whale optimization algorithm (WOA) is a Meta heuristic optimization algorithm which uses the natural behavior of the humpback whales [21], [22]. WOA has been used in finding the best feature set with performance comparison with particle swarm optimization and genetic algorithm [21]. An extensive study on WOA has been conducted by applying it in mathematical benchmark functions to analyze its potential for convergence and all other features of the optimization algorithm [22].

In this paper, three-phase AANF based control algorithm has been proposed for estimation of reference load voltage. The optimization technique for PI gains estimation in DVR for compensation of major issues like voltage sag, voltage swell, imbalances, and distortions in the supply voltage has been proposed. Proposed control algorithm has an advantage of online extraction of frequency/phase of disturbed signals. It also produces the fundamental component and its $90^{\circ}$ phase shifted component, which helps in computing the sequence components of the given signal. It uses three phase AANF based frequency extraction unit for online frequency extraction. This estimated frequency is further utilized in ANF structures in each phase for separating the fundamental component and its quadrature component of three phases. The sequence components extraction unit is used for the positive sequence components useful for the load voltage reference generation. A Whale Optimization Algorithm (WOA), the optimization approach for tuning the proportional integration (PI) controller's gains is proposed in this control algorithm because of its competitiveness compared to conventional one. The process of PI gains estimation is clearly shown with the help of figures showing the variation with respect to iteration. These estimated gains have been used in the proposed control algorithm for the fast and satisfactory operation of DVR.

\section{System Configuration}

The detailed system configuration has been presented in Fig. 1, which has mainly two parts namely power and control circuit respectively. The power circuit consists of three-phase ac supply with disturbance creating unit, sensitive/critical load, injection transformer, filter network, bi-directional converter and capacitor. Disturbances in the supply voltage $\left(v_{\text {sabc }}\right)$ have been created by the disturbance-creating unit as shown in Fig. 1 . The disturbance-creating unit consists of different types of loads connected at the same point of common coupling (PCC) with the switches $\left(\mathrm{sw}_{1}\right.$ to $\left.\mathrm{sw}_{4}\right)$ with different times $\left(\mathrm{t}_{1}, \mathrm{t}_{2} \ldots\right.$ $t_{4}$ ) of switching periods. Switching ON the inductive and capacitive loads at $t_{1}$ and $t_{2}$ respectively creates sag and swell in the supply voltage. In the same way, switching ON the three-phase unbalanced load and rectifier with RL-load at $t_{3}$ and $t_{4}$ respectively creates disturbance and unbalances in supply voltage. Resistive-Inductive (RL) load is considered as a sensitive/critical load for which the load voltage $\left(v_{\text {Labc }}\right)$ at its terminals is to be maintained at the nominal value. Injection transformer $\left(\mathrm{TF}_{\text {inj }}\right)$ with the selected transformation ration (n: 1$)$ has been used for series connection of compensation unit in series with supply and load. Filtering unit is to filterout the generated switching harmonics from the Voltage Source Converter (VSC). VSC used here is the bi-directional converter and provides bidirectional flow of energy.

The energy storage device here is capacitor $\left(\mathrm{C}_{\mathrm{DC}}\right)$ with voltage $\left(\mathrm{V}_{\mathrm{DC}}\right)$ has been maintained at its reference voltage which is measured for the progressive compensation of disturbances created in the supply voltage. The functioning of the power circuit depends on the working of the control circuit that is elaborated in the following subsection.

The control circuit consists of 3-phase AANF based frequency extraction unit, three single units of ANF structures, 3-phase sequence component extraction unit, reference load voltage generation, and gate pulse generator. The gate pulses generated in the control circuit have been used to drive the VSC in the power circuit part of the configuration for working as a bi-directional converter. The detailed explanation of the control algorithm with mathematical analysis and stability analysis has been reported in Section III.

\section{AANF Based Control Algorithm}

The effective operation of power circuit is completely dependent on performance of control circuit in generating gate pulses for VSC situated in power circuit. The proposed control algorithm is utilizing the AANF for estimating the phase/ frequency of the measured signals. Further, the estimated phase/ frequency has been taken into account while estimating the fundamental component (FCs) of the input signals. From these 


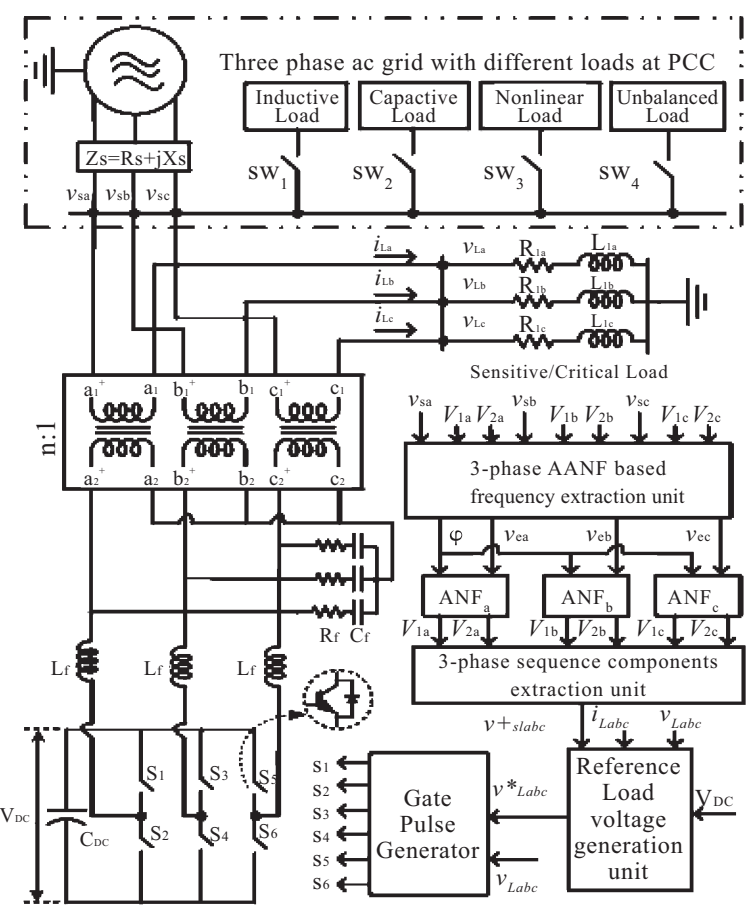

Fig. 1. DVR system with proposed control algorithm.

fundamental components, the positive sequence components (PSCs) have been computed and utilized for the reference load voltage $\left(v_{\text {Labc }}^{*}\right)$ generation. The load voltage $\left(v_{\text {Labc }}\right)$ has been sensed and it has been compared with the reference load voltage $\left(v_{\text {Labc }}^{*}\right)$ for producing the PWM pulses to drive the VSC. The details of the control algorithm has been given in the following sub-sections.

\section{A. Basics of Amplitude Adaptive Notch Filter}

The adaptive property of AANF has been inspired from the Regalia's algorithms continuous time version. According to this algorithm, considering the estimation of frequency $(\omega)$ of a signal $y(t)$ where ' $\theta$ ' is the resulting estimated frequency, it has three states $\theta$, $x_{1}$, and $x_{2}$, obey the following differential (1) to (3) [14].

$$
\begin{gathered}
\dot{x}_{1}=x_{2} \\
\dot{x}_{2}=-2 \zeta \theta x_{2}-\theta^{2} x_{1}+k y \\
\dot{\theta}=-g\left(k y-2 \zeta \theta x_{2}\right) x_{1}
\end{gathered}
$$

Where, ' $\zeta$ ', the damping factor, ' $g$ ', the adaption gain, ' $k$ ', the filter gain are the positive constants. The new AANF structure has been provided in [15],[16], which satisfies the (4) to (8). The error, $e(t)$ is calculated using (6), ' $\varepsilon$ ' and ' $\varphi$ ' represent positive constant and frequency respectively. The positive parameters damping factor $(\zeta)$, the adaption gain $(\lambda)$ which represents the speed of convergence and accuracy of the AANF.

$$
\begin{gathered}
\ddot{x}+\varphi^{2} x=2 \zeta \varphi e(t) \\
\dot{\varphi}=-\lambda x \varphi e(t) \\
e(t)=x(t)-\dot{x}
\end{gathered}
$$

$$
\begin{gathered}
\lambda=\frac{\varepsilon}{\left(1+A^{2}\right)\left(1+\mu \varphi^{2}\right)} \\
(\mathrm{O})=\left(\begin{array}{l}
x \\
\dot{x} \\
\varphi
\end{array}\right)=\left(\begin{array}{l}
\frac{-A_{1}}{w} \cos \left(w t+\psi_{1}\right) \\
A_{1} \sin \left(w t+\psi_{1}\right) \\
w
\end{array}\right)
\end{gathered}
$$

For the fundamental frequency ' $w$ ', the sinusoidal signal, AANF attains a uniform periodic orbit ' $\mathrm{O}$ ' defined as (8), where ' $A_{1}$ ', ' $\psi_{1}$ ' represent the fundamental component and phase angle respectively. From the (8), fundamental frequency ' $w$ ' is given by ' $\varphi$ ' and it is clear that, $A_{1}=\sqrt{\dot{x}^{2}+(-\varphi x)^{2}}$ where $\dot{x}=A_{1} \sin \left(w t+\psi_{1}\right)$ and $-\varphi x=A_{1} \cos \left(w t+\psi_{1}\right)$ are the fundamental component and its quadrature component respectively.

\section{B. 3-Phase AANF for Extraction of Fundamental Voltage}

From the inspiration of the concept of single phase AANF, the 3-phase AANF is formulated for compensation of voltage based power quality problems. The detailed structure of the 3-phase AANF is given in Fig. 2. Let the 3-phase input signal that is to be synchronized is defined as (9) where ' $V_{N}$, ' $w_{n}$ ', and ' $\varphi_{n}$ ' are unknown amplitudes, frequency, and phase angle respectively.

$$
v(\mathrm{t})=\sum_{\substack{N=A, B, \mathrm{C} \\ \mathrm{n}=\mathrm{a}, \mathrm{b}, \mathrm{c}}} V_{N} \sin \left(w_{n} t+\psi_{n}\right)
$$

For approximating these unknown parameters of any 3-phase signal in (9), the 3-phase AANF is described as given in the differential (10) to (14) using the (4) to (8) [15],[16], where, $\mathrm{n}=\mathrm{a}, \mathrm{b}, \mathrm{c}$ and $\mathrm{N}=\mathrm{A}, \mathrm{B}, \mathrm{C}$. Here, ' $\varphi$ ' represents the frequency and ' $\varepsilon$ ' is the positive constant. The positive parameters ' $\zeta$ ', the damping factor, ' $\lambda_{n}$ ', the adaption gain represents the accuracy and convergence speed of the AANF. Parameter ' $v_{e n}$ ' is the error voltage which is obtained by subtracting fundamental component $\left(V_{l a}\right)$ of the input signal from the input signal $\left(v_{n}\right)$.

$$
\begin{gathered}
\ddot{v}_{\mathrm{n}}+\varphi^{2} v_{n}=2 \zeta \varphi v_{e n}(t) \\
\dot{\varphi}=-\lambda v_{n} \varphi v_{e n}(t) \\
v_{e n}(t)=v_{n}(t)-\dot{v}_{n} \\
\lambda_{n}=\frac{\varepsilon}{\left(1+V_{N}^{2}\right)\left(1+\mu \varphi^{2}\right)}
\end{gathered}
$$

For the fundamental frequency ' $w_{1}$ ', 3-phase AANF is having the periodic orbit $(\mathrm{O})$ as mentioned in (14), where ' $V_{N}$ ' is the fundamental amplitude of the respective input signal $(\mathrm{N}=\mathrm{A}$, $\mathrm{B}$, and C) which is utilized to compute the adaption gain, ' $\lambda_{\mathrm{n}}$ '. The phase angles of each phase have been represented by ' $\psi_{\mathrm{n}}$ ' $(n=a, b, c)$. From the (14), the fundamental frequency of the input signal ' $w_{1}$ ' is identified as ' $\varphi$ ', the fundamental component and its quadrature component are given as $V_{N} \sin \left(w_{l} t+\psi_{n}\right)$ and $V_{N} \cos \left(w_{l} t+\psi_{n}\right)$. These two components have been separated using the separate ANF filters for each phase as shown in Fig. 1. 


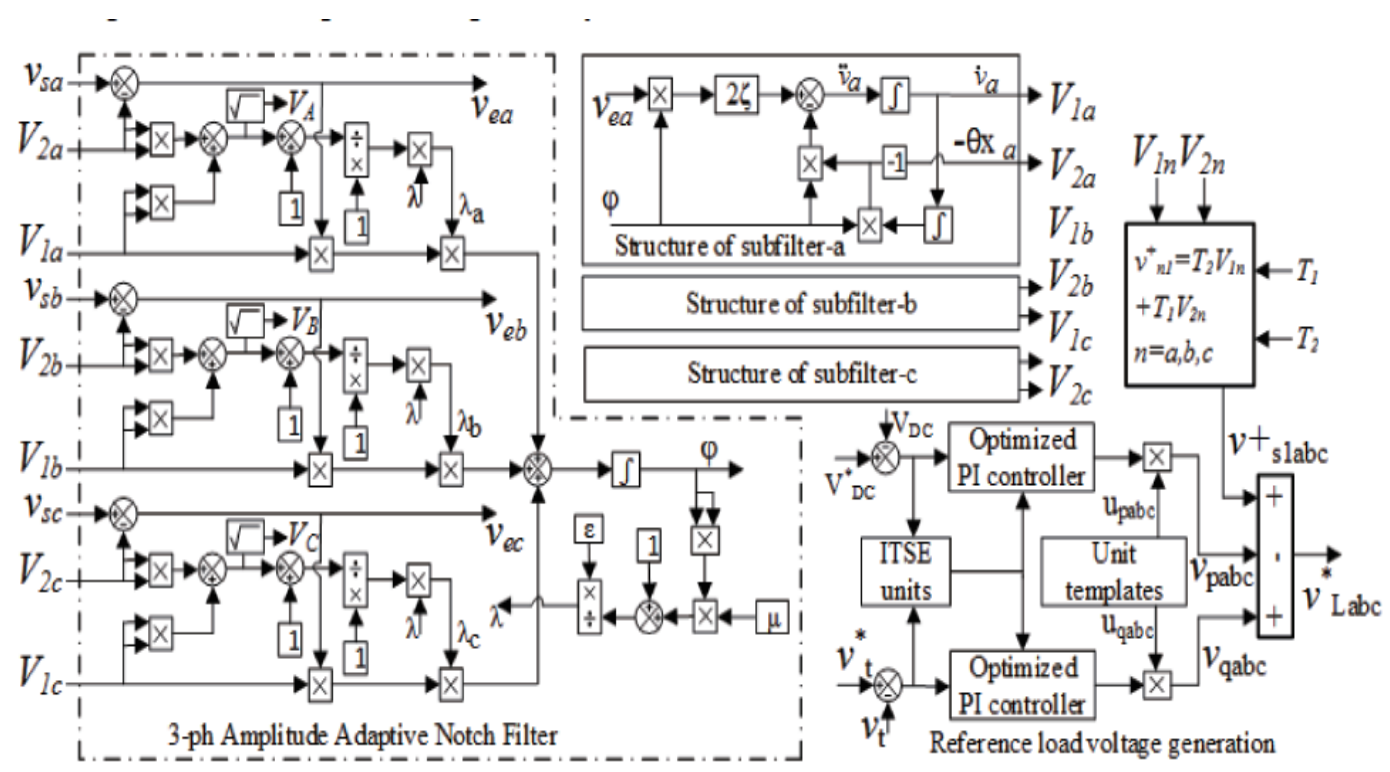

Fig. 2. Structure of AANF based control algorithm for DVR.

The details of ANF filters have been given in Fig. 2 which utilizes the error signal ' $v_{e n}$ ' and the estimated frequency ' $\varphi$ ' as inputs and produces the fundamental component $\left(V_{l n}\right)$, quadrature component $\left(V_{2 n}\right)$ as outputs given in (15) and (16).

$$
\begin{gathered}
(\mathrm{O})=\left(\begin{array}{l}
v_{n} \\
\dot{v}_{n} \\
\varphi
\end{array}\right)=\left(\begin{array}{l}
\frac{-V_{\mathrm{N}}}{w_{1}} \cos \left(w_{1} t+\psi_{n}\right) \\
V_{\mathrm{N}} \sin \left(w_{1} t+\psi_{n}\right) \\
w_{1}
\end{array}\right) \\
\dot{v}_{n}=V_{N} \sin \left(w_{1} t+\psi_{n}\right)=V_{1 n} \\
-v_{n} \varphi=V_{N} \cos \left(w_{1} t+\psi_{n}\right)=V_{2 n}
\end{gathered}
$$

Therefore, the amplitude ' $V_{N}$ ' of a particular phase is measured as $V_{N}=\sqrt{V_{1 n}^{2}+V_{2 n}^{2}}=\sqrt{\dot{v}_{n}^{2}+\left(-\varphi v_{n}\right)^{2}}$ and then utilized in the frequency estimating unit of the AANF structure and sequence component extraction unit.

\section{Sequence Components Extraction and Reference Voltage Generation}

The 3-phase voltages given in (9) have been separated into their sequence components. The fundamental and its $90^{\circ}$ phase sifted component measured using (15) and (16) is then represented by column matrix as shown in (17). The positive Sequence components (PSCs) are computed from the Fundamental Components (FCs) and Transformation Matrices $\left(\mathrm{T}_{1}, \mathrm{~T}_{2}\right)$ using $(18)[15]$.

$$
V_{1 n}=\left(\begin{array}{l}
i a \\
i b \\
i c
\end{array}\right) \text { and } V_{2 n}=\left(\begin{array}{l}
-\varphi v_{a} \\
-\varphi v_{b} \\
-\varphi v_{c}
\end{array}\right)
$$

$$
\begin{aligned}
& v_{n 1}^{+}=T_{2} V_{1 n}+T_{1} V_{2 n} \\
& T_{1}=\frac{1}{2 \sqrt{3}}\left[\begin{array}{ccc}
0 & 1 & -1 \\
-1 & 0 & 1 \\
1 & -1 & 0
\end{array}\right] ; T_{2}=\frac{1}{3}\left[\begin{array}{ccc}
1 & -1 / 2 & -1 / 2 \\
-1 / 2 & 1 & -1 / 2 \\
-1 / 2 & -1 / 2 & 1
\end{array}\right.
\end{aligned}
$$

Finally, the FPSCs of the input voltage extracted are represented as $\left(v_{\text {slabc }}^{+}\right)$and further utilized in generating the reference load voltages $\left(v_{\text {Labc }}^{*}\right)$.

Now, the reference load voltage $\left(v_{\text {Labc }}^{*}\right)$ generation has been done by using the FPSCs and Unit templates $\left(u_{p a b c}\right.$ and $\left.u_{q a b c}\right)$ and output signals of DC bus PI controller $\left(\mathrm{V}_{\mathrm{DCPI}}\right)$ and $\mathrm{AC}$ bus PI controller $\left(\mathrm{V}_{t P I}\right)$ respectively.

$$
\begin{gathered}
v_{\text {Labc }}^{*}=v_{\text {slabc }}^{+}-v_{p a b c}+v_{q a b c} \\
v_{p a b c}=V_{D C P I} \times u_{p a b c} \\
v_{q d b c}=V_{t P I} \times u_{q a b c}
\end{gathered}
$$

Where ' $u_{\text {pabc }}$ ' and ' $u_{q a b c}$ ' are calculated using the load currents $\left(i_{\text {Labc }}\right)$ sensed as shown in (23) and (24) [3].

$$
\begin{gathered}
u_{p a}=\frac{i_{l a}}{i_{A}} ; u_{p b}=\frac{i_{l b}}{i_{A}} ; u_{p c}=\frac{i_{c c}}{i_{A}} \\
u_{q a}=\frac{u_{p c}-u_{p b}}{\sqrt{3}} ; u_{q b}=\frac{3 u_{p a}+u_{p b}-u_{p c}}{2 \sqrt{3}} ; u_{q c}=\frac{-3 u_{p a}+u_{p b}-u_{p c}}{2 \sqrt{3}}
\end{gathered}
$$

Where $i_{A}=\sqrt{2 / 3\left(i_{l a}^{2}+i_{l b}^{2}+i_{l c}^{2}\right)}$

The sensed load voltage $\left(v_{\text {Labc }}\right)$ is then compared with the reference load voltage $\left(v_{\text {Labc }}^{*}\right)$ of each phase to get the load error voltage $\left(v_{\text {Leabc }}\right)$ for each phase respectively. These error signals have been passed through the high frequency triangular signal for comparison and gate pulses $\left(\mathrm{s}_{1}, \mathrm{~s}_{2}\right),\left(\mathrm{s}_{3}, \mathrm{~s}_{4}\right)$, and $\left(\mathrm{s}_{5}, \mathrm{~s}_{6}\right)$ have been generated for each arm of the VSC respectively. 


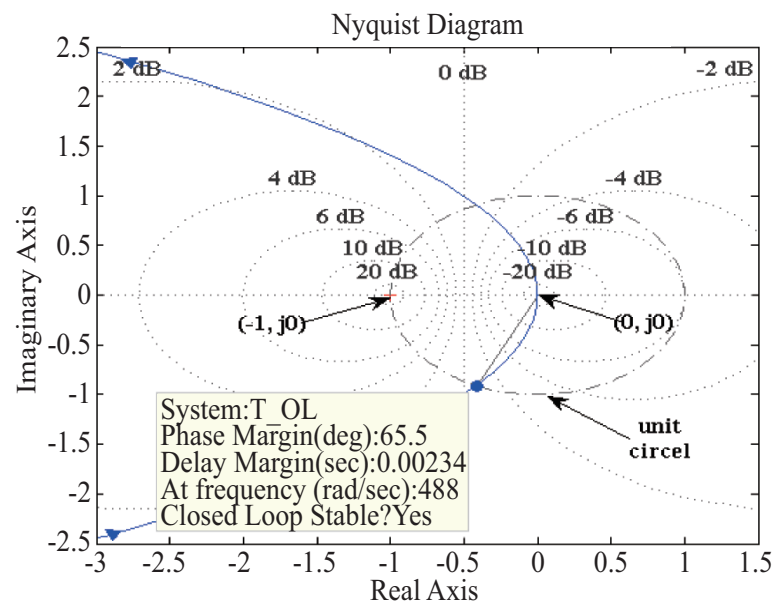

Fig. 3. Nyquist plot for open loop Transfer Function (30).

\section{Stability Analysis of Filter}

From the (15), it is clear that ' $\dot{v}_{n}$ ' is the fundamental component of the input signal ' $v_{s}$ ' and it is represented by ' $v_{f}$ '. Therefore,

$$
\dot{v}_{n}=v_{f}
$$

The Laplace Transform of the (10), (12) and (25) are obtained as (26), (27) and (28) respectively.

$$
\begin{aligned}
& s^{2} V_{n}(\mathrm{~s})+\varphi^{2} V_{n}(\mathrm{~s})=2 \zeta \varphi V_{e}(\mathrm{~s}) \\
& V_{e}(s)=V_{s}(s)-s V_{n}(s) \\
& \quad s V_{n}(\mathrm{~s})=V_{f}(\mathrm{~s})
\end{aligned}
$$

Substituting (28) in (26) and (27) and simplified to obtain the closed-loop transfer function of fundamental signal ' $V_{f}(s)$ ' to input signal ' $V_{s}(s)$ ' as in the (29).

$$
\frac{V_{f}(\mathrm{~s})}{V_{s}(\mathrm{~s})}=\frac{2 \zeta \varphi s}{s^{2}+2 \zeta \varphi s+\varphi^{2}}=T_{C L}
$$

Where $T_{C L}=\frac{G(\mathrm{~s})}{1+G(\mathrm{~s}) H(\mathrm{~s})}, T_{O L}=G(\mathrm{~s}) H(\mathrm{~s})$

$$
G(\mathrm{~s}) \mathrm{H}(\mathrm{s})=\frac{2 \zeta \varphi s+\varphi^{2}}{s^{2}}=\frac{\varphi^{2}\left(1+\frac{2 \zeta}{\varphi} \mathrm{s}\right)}{s^{2}}=\frac{k(1+\mathrm{Ts})}{s^{2}}
$$

Hence, the open loop transfer function is derived from the closed loop transfer function as in the (30), Where $k=\varphi^{2}$ and $T=2 \zeta / \varphi$. The selection of the parameters ' $k$ ' and ' $\mathrm{T}$ ' are based on the selection of ' $\zeta$ ' and ' $\varphi$ '. The damping factor, ' $\zeta$ ' is associated with the damping property of the filter, so it is selected as 0.707 to avoid the dampings in the response. For selected value values of ' $\zeta$ ' and ' $\varphi$ ', the parameters in the open loop transfer function ' $k$ ' and ' $T$ ' are found. The stabilty of the filter is examined using the Nyquist stability criteria as shown in Fig. 3. The stability analysis of the filter is observed for the



Fig. 4. PI controller gains estimation flow chart using WOA.

response of the fundamental component ' $V_{f}(s)$ ' to input signal ' $V_{s}(s)$ '. For the selected parameters of the open loop transfer function ' $k$ ' and ' $T$ ', closed-loop stability can be observed by Nyquist stability analysis from the open loop transfer function $\left(\mathrm{T}_{\mathrm{OL}}\right)$ as given in (30). The AANF parameters, ' $\varepsilon$ ' and ' $\mu$ ' are set to 10000 and 0.00001 for a satisfactory response, the adaption gain ' $\lambda$ ' is computed accordingly.

\section{E. Estimation of PI Gains Using WOA}

A Whale Optimization Algorithm (WOA), the optimization approach for tuning the PI controller's gains is proposed in this control algorithm. PI gains tuning is another task in the control algorithm for most of the power electronics application. Even though, methods of automatic PI controller tuning are available, it has been more practice of tuning PI controller manually (i.e. trial and error) due to occurrence of ineffective solution with automatic tuning methods. The error, $e(t)$ of actual and reference signals can be modeled as any one of the performance indices for defining the cost function $\left(f_{\text {cost }}\right)$. Here, the performance index, Integral of Time Squared Error (ITSE) is considered for cost function. It is expressed as,

$$
f_{\text {cost }}=\int t e^{2}(t) d t
$$

The WOA starts optimization with a randomly selected an initial positions for each and every search agents. For the satisfactory solution, after many tests, the lower $(l)$ and upper ( $u$ ) bounds are set to ' 0 ' and ' 30 '. Number of agents $(n)$, the maximum number of iteration $\left(I_{\max }\right)$ have been set to 20 and 10 . The dimension $(d)$ of the search agent has been set to ' 4 ' i.e. Gains of two PI controllers are named as $\left(\mathrm{k}_{\mathrm{p} 1}, \mathrm{k}_{\mathrm{i} 1}\right)$ and $\left(\mathrm{k}_{\mathrm{p} 2}, \mathrm{k}_{\mathrm{i} 2}\right)$ respectively. Fig. 4. shows the flow chart of WOA for tuning the PI controllers' gains, where ' $i$ ' represents the present iteration. 


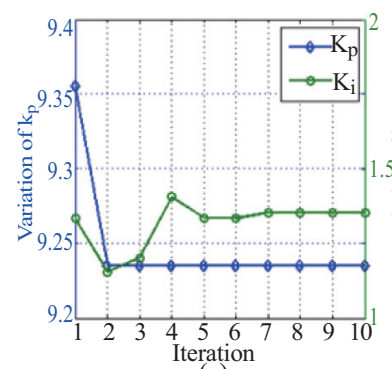

(a)

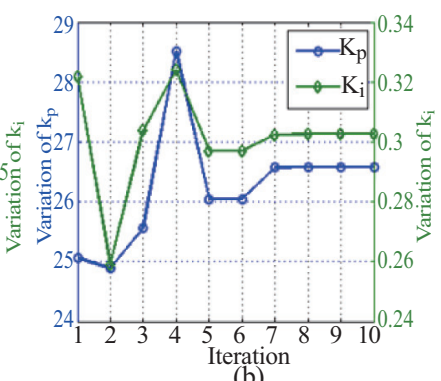

(b)
Fig. 5. Variation of PI gains with respect to iterations (a) DC-Link PI and (b) terminal voltage PI.

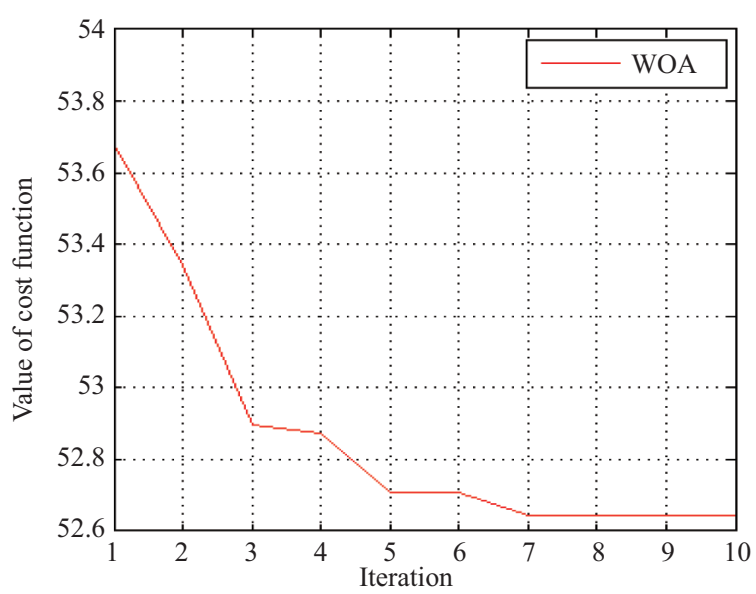

Fig. 6. Convergence curve of cost function with respect to iterations.

Optimal values of PI-controller gains are obtained from the leader position $(x)$. The mathematical description of WOA is as follows.

The position vector $(x)$ and distance (D) of each search agent (leader whale) are updated using (32) and (33). Where, ' $p$ ' is the random number in the range $(0,1), b=1$, ' $l$ ' are constants and ' $\mathrm{L}$ pos" represents the position of leader (leading) whale. $A, C$ are the coefficient of vectors measured using (34).

$$
\begin{aligned}
& \left.\left.\begin{array}{l}
D=a b s\left(C \times x \_\right. \text {rand } \\
\left.x_{i, d}=x_{i, d}\right)
\end{array}\right\} \ldots i f \ldots a b s(A) \geq 1\right)
\end{aligned}
$$

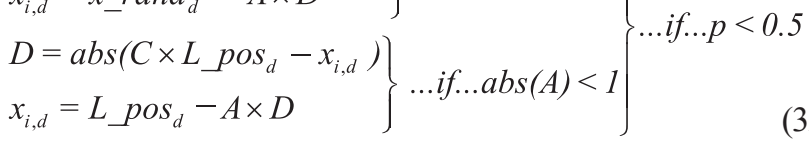

$$
\begin{aligned}
& \left.\begin{array}{l}
D=\operatorname{abs}\left(L \_\operatorname{pos}_{d}-x_{i, d}\right) \\
x_{i, d}=D \times e^{b \times l} \times \cos (2 \pi l)+L \text { pos }_{d}
\end{array}\right\} \ldots i f \ldots p \geq 0.5 \\
& A=(2 \times \operatorname{rand}()-1) \times a_{1} ; C=2 \times \operatorname{rand}() \\
& \text { Where, } a_{1}=\left(1-\frac{i}{I_{\max }}\right) \times 2 ; a_{2}=-\left(1+\frac{i}{I_{\max }}\right) \text {; } \\
& l=\left(a_{2}-1\right) \times \operatorname{rand}()+1 ; \text { and } p=\operatorname{rand}()
\end{aligned}
$$

The variation in the position of variables $\left(\mathrm{k}_{\mathrm{p} 1}, \mathrm{k}_{\mathrm{i} 1}, \mathrm{k}_{\mathrm{p} 2}\right.$, and $\left.\mathrm{k}_{\mathrm{i} 2}\right)$ with respect to iteration can be seen in Fig. 5(a) and (b). During this iterative process, the convergence curve has been depicted in Fig. 6. It is observed that the cost function is stabled at $7^{\text {th }}$ iteration and continuing with the same cost function value i.e.

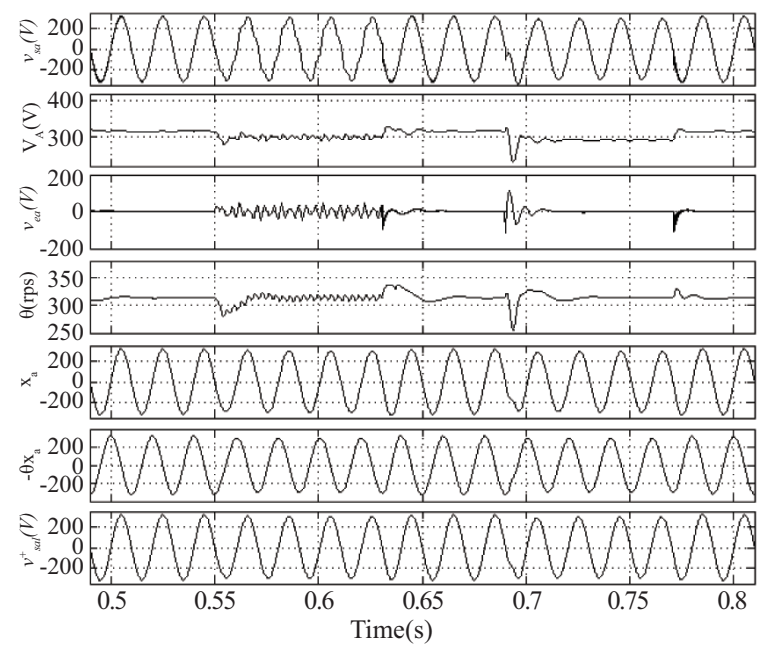

Fig. 7. Internal signals of AANF for extracting FPSCs.

52.65. From the Fig. 5(a) and (b), at least by $7^{\text {th }}$ iteration the variable $\left(\mathrm{k}_{\mathrm{p} 1}, \mathrm{k}_{\mathrm{i} 1}, \mathrm{k}_{\mathrm{p} 2}\right.$, and $\left.\mathrm{k}_{\mathrm{i} 2}\right)$ are settled to their optimized values $9.23,1.375,26.52$, and 0.31 respectively. These optimized values of PI controller gains are to be used in the proposed control algorithm for the acceptable performance in the threephase DVR connected system.

\section{Simulation Results Discussion}

The developed AANF based control algorithm is tested with three-phase DVR connected system in compensating the voltage sag/swell, distortions, and unbalance for evaluation. This complete system with AANF based control algorithm is simulated using MATLAB software-based simulator. The solver used in this simulation with a sampling time of $20 \mu \mathrm{S}$. It is to be noted that simulation results and performance of AANF based control algorithm have been considered for distortions and unbalance. The performance investigation of DVR with AANF based control algorithm has been carried out under various conditions such as voltage sag/swell, distortions, and unbalance. The system parameters for the simulation work have been given in Appendix A.

\section{A. Performance of AANF Based Control Algorithm}

The simulation performance of AANF based control algorithm in extracting the FPSCs and generating the reference load voltage $\left(v_{\text {Labc }}^{*}\right)$ with distorted and unbalanced supply voltage $\left(v_{s a b c}\right)$ is presented in this section. Fig. 7 shows the extraction of FPSCs from the distorted and unbalanced supply voltage of phase ' $\mathrm{a}$ ' $\left(v_{s a}\right)$.The amplitude of phase ' $\mathrm{a}$ ', $\mathrm{V}_{\mathrm{A}}$, error, $v_{e a}$ of phase ' $a$ ', and the estimated frequency, $\theta$ are the internal signals of frequency extraction unit of control algorithm shown in this figure. The fundamental component, ' $\dot{\mathrm{X}}_{\mathrm{a}}$ ' and its $90^{\circ}$ phase shifted component, ' $-\theta \mathrm{x}_{\mathrm{a}}$ ' which have been computed from the single-phase structure of AANF presented in this figure. From Fig. 7, it is observed that the variation of frequency during the dynamics can be seen cleary in subplot (4) of Fig. 7 at $0.55 \mathrm{sec}$ and $0.69 \mathrm{sec}$ for distorted and unbalanced 


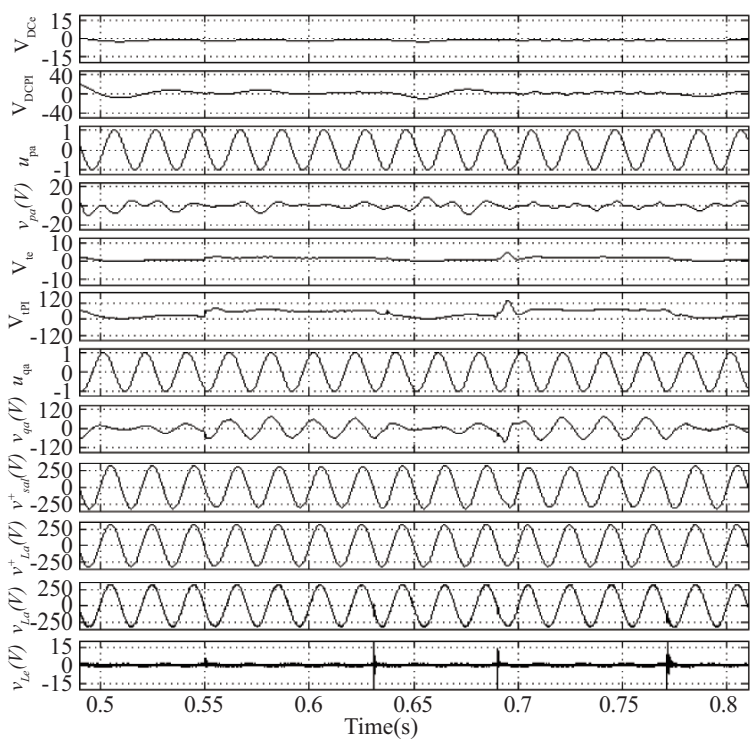

Fig. 8. Internal signals of a proposed control algorithm for generating reference load voltage.

supply. The fundamental and its quadrature components have been used for the Sequence Components (SCs) computation. Computed Fundamental Positive Sequence Component (FPSC) of the supply voltage $\left(v_{\text {sla }}^{+}\right)$has been depicted in subplot (8) of Fig. 7. Fig. 8 shows the internal signals control algorithms in generating the reference load voltage with supply voltage distortions and unbalance. Inputs to the controllers $\left(\mathrm{V}_{\mathrm{DCe}}\right.$ and $\left.\mathrm{V}_{t e}\right)$, outputs of controller $\left(\mathrm{V}_{\mathrm{DCPI}}, \mathrm{V}_{t P I}\right)$, unit templates $\left(u_{p a}, u_{q a}\right)$, and signals obtained by multiplying unit templates with PI controller outputs, $\left(v_{p a}, v_{q a}\right)$ have been presented in this graph. The FPSC of supply voltage $\left(v_{\text {sla }}^{+}\right)$, reference load voltage $\left(v^{*}{ }_{L a}\right)$ computed by $(20)$, and actual load voltage of phase 'a' $\left(v_{L a}\right)$ to compare with $\left(v_{L a}^{*}\right)$ are reported here in Fig. 8 . The error load voltage signal $\left(v_{l e}\right)$ is further passed through highfrequency carrier signal to generate PWM gate pulse signals $\left(\mathrm{s}_{1}\right.$, $\mathrm{S}_{2} \ldots . . . \mathrm{s}_{6}$ ) for IGBTs used in the VSC of the power circuit of DVR connected system.

\section{B. Performance of DVR Using AANF Based Control Algo- rithm}

As mentioned in the Section-II, voltage sag, voltage swell, distortions in voltage waveform, and imbalance in the supply voltage have been created by joining the different types of loads at same PCC each for the duration of 4 cycles at $0.25 \mathrm{sec}, 0.39 \mathrm{sec}$, $0.55 \mathrm{sec}$, and $0.69 \mathrm{sec}$ respectively. Fig. 9(a) represents the overall performance of the DVR system with proposed control algorithm in presence of sag, swell, distortions, and imbalance in the supply voltage. Three-phase supply voltage $\left(v_{s a b c}\right)$ with all the dynamics, compensated voltages $\left(v_{c a b c}\right)$, and the load voltage $\left(v_{L a b c}\right)$ at the load terminal after compensation have been depicted in the subplots (1-5) of Fig. 9(a). It has been observed that the load voltage is free from the disturbances appended to the supply voltage due to effective compensation by DVR. Three-phase load current $\left(i_{L a b c}\right)$, magnitude of load terminal

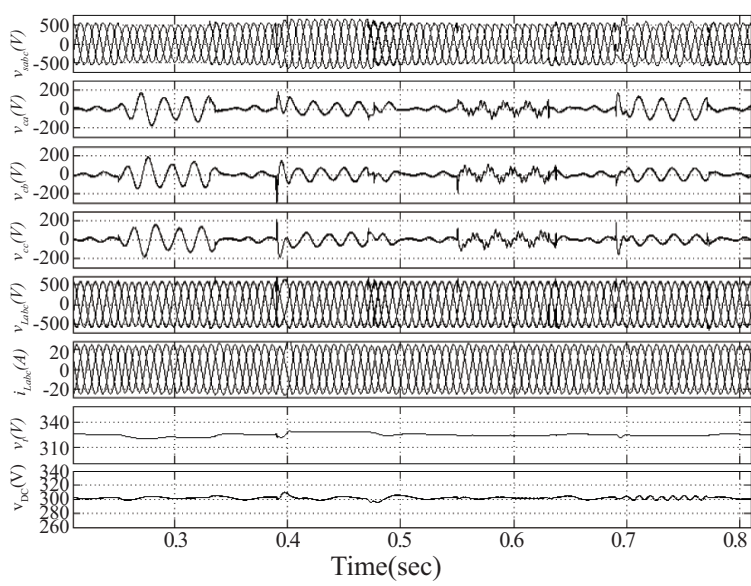

(a)

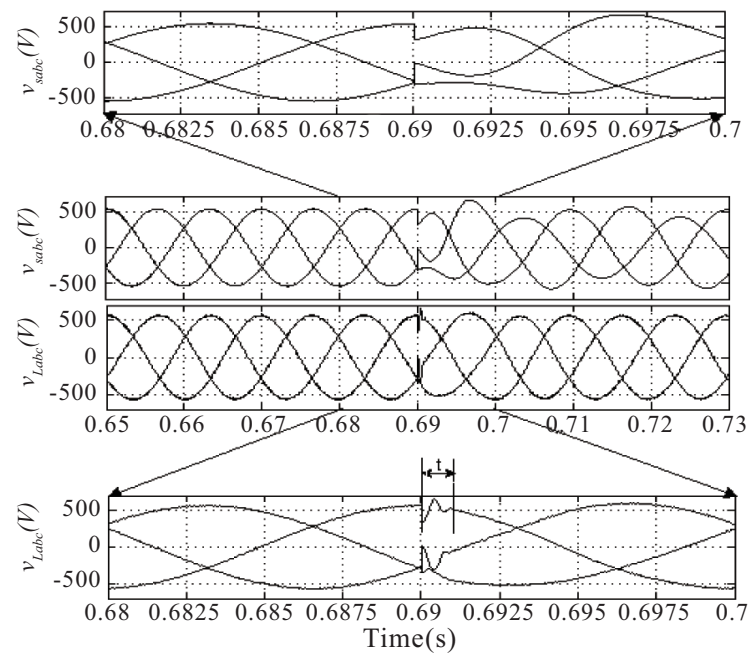

(b)

Fig. 9. (a) Performance of DVR in compensation of voltage sag, voltage swell, voltage distortions, and voltage imbalance using AANF based control algorithm. (b) Response time of DVR in compensation of voltage imbalance.

voltage $\left(\mathrm{V}_{t}\right)$, and DC-Link voltage $\left(\mathrm{V}_{\mathrm{DC}}\right)$ has been shown in subplots (6-8). PI controllers are effectively maintaining the DC-Link voltage and terminal voltages at their reference levels. The DVR with the proposed AANF based control algorithm is producing the effective solution for the mentioned problems associated with a supply voltage in the distribution system. Fig. 9(b) shows the response time of DVR for compensating an imbalance in the supply voltage by using AANF control algorithm. It is to be noted that the Fig. 9(b) contains the supply voltage and its corresponding load voltage during the unbalances in the supply voltage. The subplot 1 in Fig. 9(b) represents the Zoom-in figure of subplot 2 and subplot 4 represents the Zoom in figure of subplot 3 of the same figure. From the Fig. 9(b), it is clear that the DVR with AANF based control algorithms is able to compensate the unbalances in the supply voltage within the quarter (1/4) cycle.

The steady state performance of the DVR has been described by considering the distortions in the supply voltage depicted in Fig. 10. Fig. 10(a)-(c) represents the distorted supply voltage $\left(v_{s a}\right)$, compensated load voltage $\left(v_{L a}\right)$, and load current $\left(i_{L a}\right)$ 


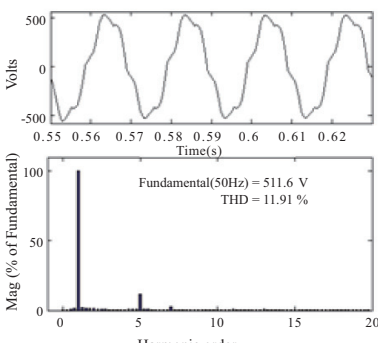

(a)



(b)
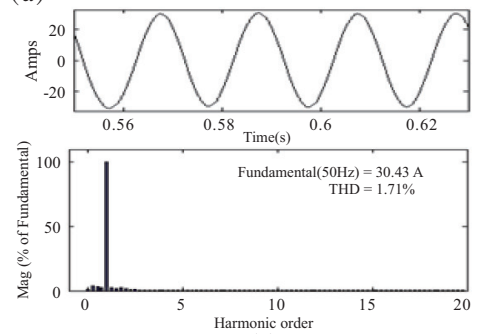

(c)

Fig.10. (a) Supply voltage of phase ' $a$ ' and its THD (b) Load voltage of phase 'a' and its THD and (c) Load current of phase 'a' and its THD.

and their respective Total Harmonic Distortions (THDs). The distorted supply voltage shown in Fig. 10(a) contains the harmonics of THD $11.91 \%$ with a fundamental voltage of $511 \mathrm{~V}$. After compensation by the DVR the load voltage is free from higher order harmonics with THD of $2.45 \%$ and fundamental voltage of $564.95 \mathrm{~V}$ as shown in Fig. 10(b). Similarly, the load voltage of THD $1.71 \%$ and fundamental current of $30.43 \mathrm{~A}$ are presented in Fig. 10(c). It is clearly understood that the levels of THDs obtained in the load voltage and load currents are under the standards of IEEE Std. 519-2014.

\section{Test Results Discussion}

A prototype DVR with proposed AANF based control algorithm has been built and programmed with field-programmable gate array (FPGA) based processor using OP-5142 real time simulator. The test results have been recorded using DSOX-2004A, a 4-channel DSO and Fluke 43B, a power quality analyzer. For validation of proposed control algorithm, AANF in three-phase DVR, its internal signals have been observed at $45 \mu \mathrm{sec}$ sampling time. The dynamic performance has been observed during sag, distortions, and imbalances in the supply voltage. The steady-state results have been recorded during distortions in the source voltage. Throughout the test, the switching frequency of VSC has been maintained at $5 \mathrm{kHz}$. It is to be noted that the values of internal signals of AANF control algorithm reported in Fig. 11(a)-(e) are in 'phase to ground', whereas the values of signals reported in Fig. 12(a)-(c) to Fig. 14(a)-(c) are in 'phase to phase'. The parameters for the test setup are given in the Appendix B.

\section{A. Performance Evaluation of AANF Based Control Algo- rithm}

The control algorithm proposed in this paper has been

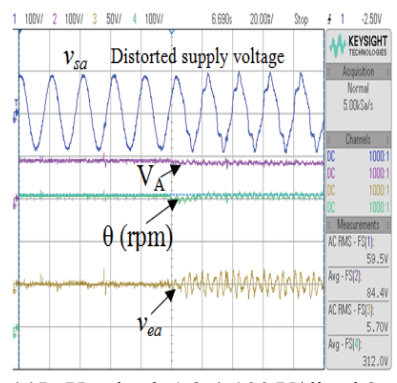

(a)In Y-axis:ch 1,2,4-100 V/div,ch3$50 \mathrm{~V} / \operatorname{div} ; \mathrm{In} \mathrm{X}$-axis:20 ms/div

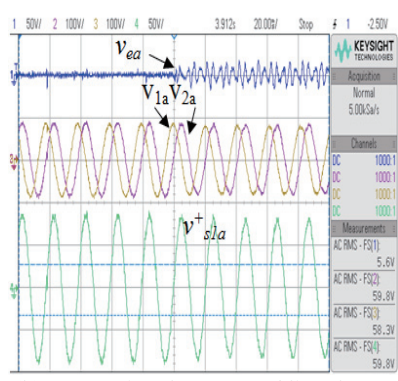

(b) In Y-axis: ch1,4-50 V/div, ch2,3$100 \mathrm{~V} /$ div; In X-axis: $20 \mathrm{~ms} / \mathrm{div}$

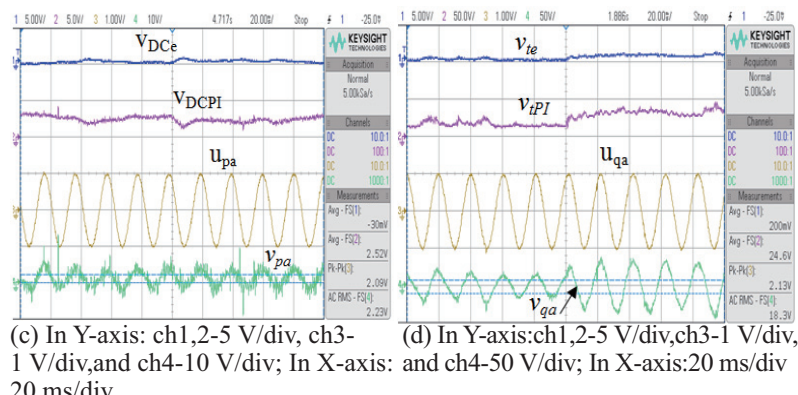

$20 \mathrm{~ms} / \mathrm{div}$

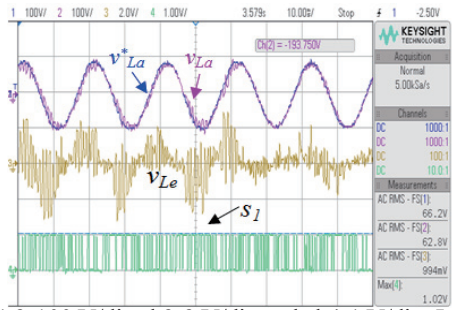

(e) In Y-axis: ch1, 2-100 V/div,ch3-2 V/div, and ch4-1 V/div; In X-axis:10 ms/div

Fig. 11. Internal signals of control algorithm (a) $v_{s a}, \mathrm{~V}_{\mathrm{A}}, v_{e a}, \theta,(\mathrm{b}) v_{e a}, \mathrm{~V}_{1 \mathrm{a}}, \mathrm{V}_{2 \mathrm{a}}$, $v_{s a}^{+},(\mathrm{c}) \mathrm{V}_{\mathrm{DCe}}, \mathrm{V}_{\mathrm{DCPI}}, \mathrm{u}_{\mathrm{pa}}, v_{p a}$, (d) $v_{t e}, v_{t P I}, \mathrm{u}_{\mathrm{qa}}, v_{q a}$ and (e) $v_{L a}^{*}, v_{L a}, v_{L e}, \mathrm{~S}_{1}$.

evaluated by observing its performance in extracting the FPSCs of the supply voltage $\left(v_{\text {slabc }}^{+}\right)$from the distorted supply voltage $\left(v_{\text {sabc }}\right)$ and generation of reference load voltages $\left(v_{\text {Labc }}^{*}\right)$. The internal signals of control algorithm presented in Fig. 11(a)(e) are of phase 'a' only and those of phase 'b' and 'c' are analogous.

The internal signals of AANF based frequency extraction unit with its input signal $\left(v_{s a}\right)$, are amplitude, $\left(\mathrm{V}_{\mathrm{A}}\right)$, error $\left(v_{e a}\right)$, and estimated frequency $(\theta)$ have been given in Fig. 11(a). The frequency estimated here is approximately equal to $314 \mathrm{rpm}$, which corresponds to the nominal frequency of the system. Fig. 11(b) shows the outputs of single ANF unit, fundamental and its $90^{\circ}$ phase shifted components $\left(\mathrm{V}_{1 \mathrm{a}}\right.$ and $\left.\mathrm{V}_{2 \mathrm{a}}\right)$, and its positive sequence component $\left(v_{\text {sla }}^{+}\right)$along with error $\left(v_{e a}\right)$ signal. Thus estimated FPSCs $\left(v_{\text {slabc }}^{+}\right)$have been used in the generation of reference load voltage. Fig. 11(c), represents the inputs of DCPI controller $\left(\mathrm{V}_{\mathrm{DCe}}\right)$, output of DC-PI controller $\left(\mathrm{V}_{\mathrm{DCPI}}\right)$, inphase unit template $\left(\mathrm{u}_{\mathrm{pa}}\right)$, and signal obtained by $(21),\left(\mathrm{v}_{p a}\right)$. Similarly, Fig. 11(d), represents the input of terminal voltage PI controller $\left(\mathrm{V}_{t e}\right)$, output of terminal voltage PI controller $\left(\mathrm{V}_{t P I}\right)$, quadrature unit templates $\left(\mathrm{u}_{\mathrm{pa}}\right.$ and $\left.\mathrm{u}_{\mathrm{qa}}\right)$, and signal obtained by (22), $\left(v_{q a}\right)$. These figures depict the acceptable performance 

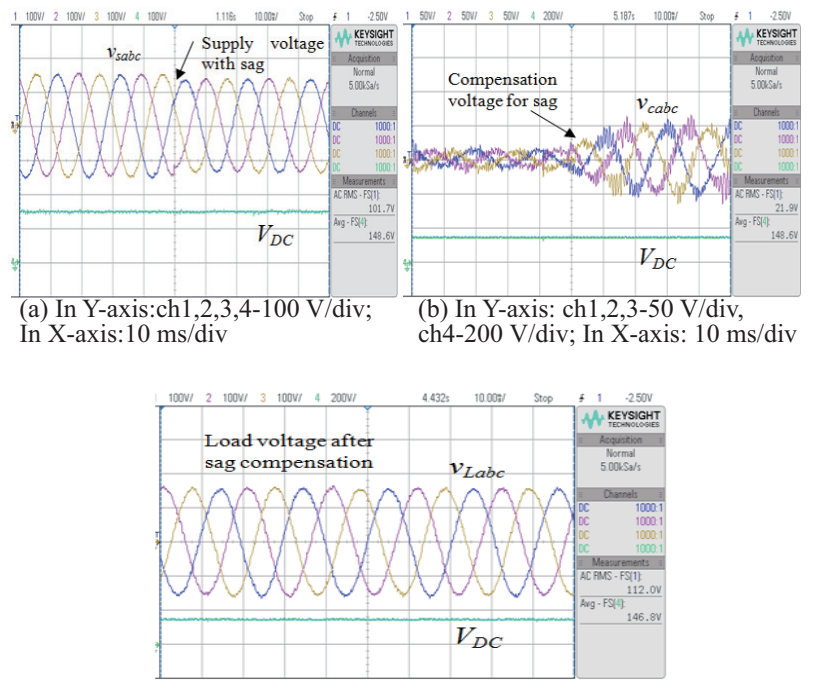

(c) In Y-axis:ch1,2,3-100 V/div,ch4-200 V/div; In X-axis:10 ms/div

Fig. 12. Test results showing sag compensation (a) supply voltage $\left(v_{\text {sabc }}\right)$ with sag (b) compensated voltage $\left(v_{c a b c}\right)$ and (c) Load voltage after compensation $\left(v_{\text {Labc }}\right)$.
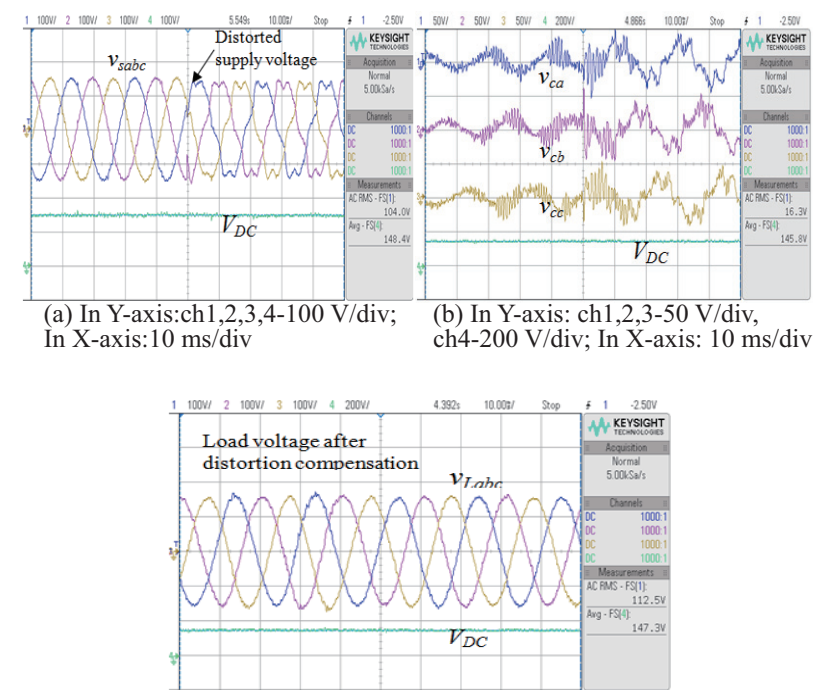

(c) In Y-axis:ch1,2,3-100 V/div,ch4-200 V/div;In X-axis:10 ms/div

Fig. 13. Test results showing distortions compensation (a) supply voltage $\left(v_{\text {sabc }}\right)$ with distortions (b) compensated voltage $\left(v_{c a b c}\right)$ and (c) Load voltage after compensation $\left(v_{L a b c}\right)$.

of PI controllers in maintaining values at their respective reference levels. Fig. 11(e), shows the comparison of reference load voltage, $\left(v_{L a}^{*}\right)$ and actual load voltage, $\left(v_{L a}\right)$ of phase ' $\mathrm{a}$ ', their corresponding error $\left(v_{L e}\right)$, and switching pulse $\left(\mathrm{s}_{1}\right)$. The generated PWM pulse $\left(s_{1}, s_{2} \ldots . s_{6}\right)$ have been given to IGBTs in VSC. This makes the DVR system with AANF based control algorithm to function satisfactorily.

\section{B. Overall Test Performance Evaluation of Three Wire DVR}

The performance analysis of DVR with the proposed control algorithm has been analyzed in both dynamic and steady states. Fig.12(a)-(c) to Fig.14(a)-(c)is interpreting the overall

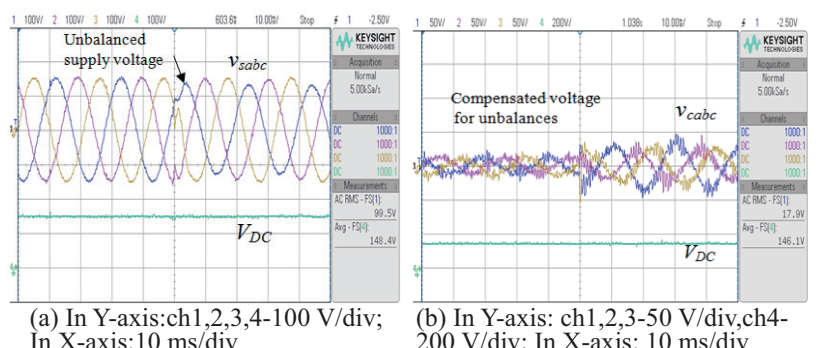

In X-axis: $10 \mathrm{~ms} / \mathrm{div} \quad 200 \mathrm{~V} /$ div; In X-axis: $10 \mathrm{~ms} / \mathrm{div}$

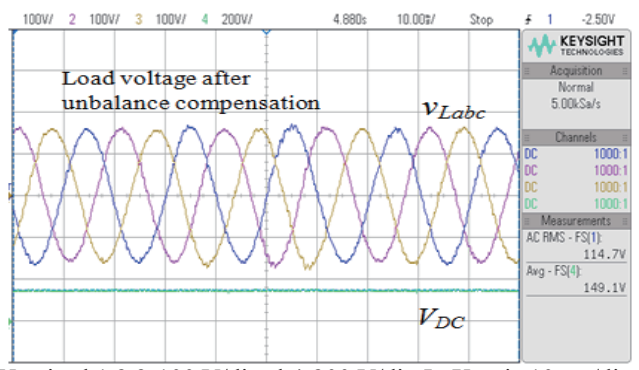

(c) In Y-axis:ch1,2,3-100 V/div,ch4-200 V/div;In X-axis:10 ms/div

Fig. 14. Test results showing unbalance compensation (a) supply voltage $\left(v_{\text {sabc }}\right)$ with unbalance $(\mathrm{b})$ compensated voltage $\left(v_{c a b c}\right)$ and (c) Load voltage after compensation $\left(v_{L a b c}\right)$.

performance of DVR when the supply voltage is imposed with sag, distortions, and unbalances due to various reasons respectively.

Fig. 12(a)-(c) depicts the three phase supply voltage $\left(v_{\text {sabc }}\right)$ with sag, compensating voltage $\left(v_{c a b c}\right)$, and load voltage after compensation $\left(v_{L a b c}\right)$. The supply voltage with sag is found to be $101 \mathrm{~V}$ RMS whereas that of the load voltage after compensation is $112 \mathrm{~V}$ RMS with compensated voltage of $21 \mathrm{~V}$ RMS. Fig. 13 (a)-(c) shows the distorted three supply voltage $\left(v_{\text {sabc }}\right)$ with 104 $\mathrm{V}$ RMS, compensating voltage $\left(v_{c a b c}\right)$ of $16 \mathrm{~V} \mathrm{RMS}$, and load voltage after compensation $\left(v_{\text {Labc }}\right)$ is of $112.5 \mathrm{~V}$ RMS. Three phase supply voltage $\left(v_{s a b c}\right)$ with unbalances, compensating voltage $\left(v_{c a b c}\right)$, and load voltage after compensation $\left(v_{\text {Labc }}\right)$ are presented in Fig. 14(a)-(c). The supply voltage including unbalance is found to be $99.5 \mathrm{~V}$ RMS whereas that of the load voltage after compensation is $114.7 \mathrm{~V}$ RMS having a compensated voltage of $17.9 \mathrm{~V}$ RMS. It is to be clear that, all the RMS values mentioned in this section are not accurate values of dynamics because DSO screen displaying portion contains both normal state and dynamic state. In all the cases the DC-Link voltage is seen maintaining at its reference value i.e. $150 \mathrm{~V}$.

\section{Harmonics Analysis}

During the supply voltage distortion, the steady-state performance of the system has been studied for the harmonic analysis of DVR performance. This analysis has been done by measuring the Total Harmonic Distortion (THD) of corresponding waveforms of the Source voltage $\left(v_{s a}\right)$, Load voltage $\left(v_{L a}\right)$, and Load current $\left(i_{L a}\right)$ of phase 'a' as reported in Fig. 15(a)-(e). The supply voltage with distortions having RMS voltage of $100 \mathrm{~V}$ of $12.3 \%$ THD are shown in Fig. 15 (a) and 


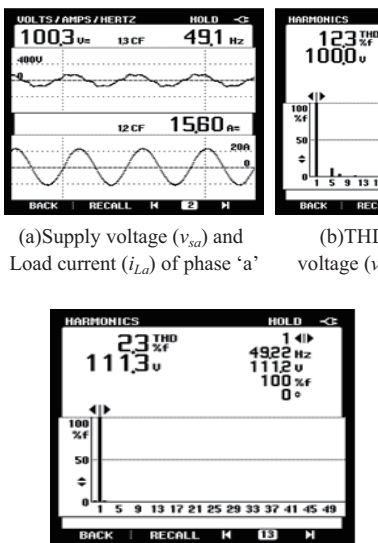

(d)THD of Load voltage $\left(v_{L a}\right)$ of phase '

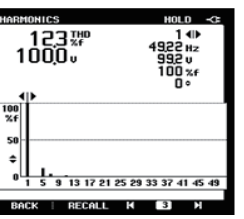

b)THD of Supply

oltage $\left(v_{s a}\right)$ of phase ' $\mathrm{a}$ '

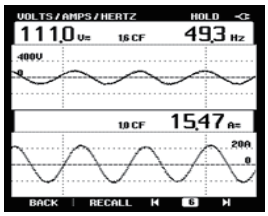

(c)Load voltage $\left(v_{L a}\right)$ and Load current $\left(i_{L a}\right)$ of phase ' $\mathrm{a}$ '

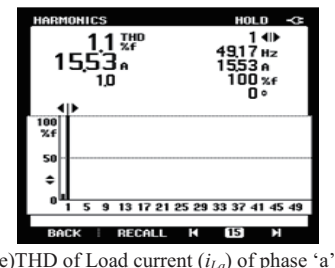

Fig.15. Test results showing steady state performance of DVR.

(b). Fig. 15(c) and (d) represents the load voltage of $110 \mathrm{~V}$ RMS with $2.3 \%$ THD respectively. The load current is also checked for its harmonics, it has been observed that the load current of phase ' $\mathrm{a}$ ' is shown in Fig. 15(e) is having the RMS value $15 \mathrm{~A}$ of current with $1.1 \%$ THD. From the steady-state analysis, it is clearly shown that the compensated load voltages and load currents have been found to be in the range of IEEE Std 519-2014.

\section{CONCLUSIONS}

Three-phase AANF based control algorithm has been developed for DVR. With the proposed control algorithm, DVR has been used for compensating the different types of voltage related issues namely, voltage sag, voltage swell, voltage distortions, and imbalance in the supply voltage. WOA based PI controller gains estimation used in this control algorithm has been providing the approximate PI gains and helping in the speedup of the control process. The simulation study has been done when the supply is imposed with all aforesaid issues. However, the discussion of test results has been presented for three cases voltage sag, distortions, and unbalances in the supply voltage. It has been observed that the DVR with proposed control algorithm producing the satisfactory performance in all the cases. Distortions in supply voltage have been compensated by DVR and the load voltage has seen to be distortion free and within the range of IEEE Std. The PI gains yielded by WOA optimization technique are well utilized in maintaining the DCLink voltage and terminal voltage at their respective reference levels. The main advantages of proposed three-phase AANF based control algorithm, with WOA optimization technique observed are listed as follows:

- Online estimation of magnitude (A), frequency/phase $(\theta)$, fundamental and its $90^{\circ}$ phase shifted components, and sequential components of a given distorted signal.

- PLLs and Transformations are not required, so that the computational burden on the control algorithm is reduced.

- PI gains are estimated very accurately within less time as compared to manual tuning.

Observing the above said benefits with proposed AANF control algorithm, DVR is able to compensate all the mentioned power quality indices. The validation of proposed control algorithm has been done by using the simulation and laboratory results of DVR.

\section{APPENDIX A}

\section{System Parameters for Simulation Performance}

AC grid- $400 \mathrm{~V}, 50 \mathrm{~Hz} ; 15 \mathrm{kVA}$ load with 0.85 p.f. (Lagg.); $\mathrm{V}_{\mathrm{s}}=0.7 * 231=162 \mathrm{~V} ; i_{\text {Load }}=21.65 \mathrm{~A} ; \mathrm{kVA}_{\mathrm{TF}}=3 * 162 * 21.65 / 1000=$ $10.52 \mathrm{kVA} \approx 11 \mathrm{kVA}, 200 / 100 \mathrm{~V} ; \mathrm{V}_{\mathrm{DC}}=300 \mathrm{~V} ; \mathrm{C}_{\mathrm{DC}}=3300 \mu \mathrm{F} ; \mathrm{L}_{f}=$ $1.5 \mathrm{mH} ; \mathrm{R}_{f}=6 \Omega$ and $\mathrm{C}_{f}=10 \mu \mathrm{F}$; Cut of frequency of low pass filter at DC bus $=10 \mathrm{~Hz}$, Cut of frequency of low pass filter at $\mathrm{AC}$ bus $=12$ $\mathrm{Hz}$, Switching frequency of VSC $\left(f_{s w}\right)=12 \mathrm{kHz}$ : Sampling time $\left(t_{s}\right)$ $=20 \mu \mathrm{sec}$.

\section{APPENDIX B}

\section{System Parameters for Test Performance}

AC grid- $110 \mathrm{~V}, 50 \mathrm{~Hz} ; 3 \mathrm{kVA}$ load with 0.85 p.f. (Lagg.); ( $\left.\mathrm{i}_{\mathrm{L}}\right)$ $=15.74 \mathrm{~A} ; \mathrm{kVA}_{\mathrm{T} / \mathrm{F}}=2 \mathrm{kVA}, 100 / 50 \mathrm{~V} ; \mathrm{V}_{\mathrm{DC}}=150 \mathrm{~V} ; \mathrm{C}_{\mathrm{DC}}=3300 \mu \mathrm{F}$; $\mathrm{L}_{f}=1 \mathrm{mH} ; \mathrm{R}_{f}=3 \Omega$ and $\mathrm{C}_{f}=20 \mu \mathrm{F}$; Switching frequency of $\operatorname{VSC}\left(f_{s w}\right)=5 \mathrm{kHz}$, Sampling time $\left(t_{s}\right)=45 \mu \mathrm{sec}$.

\section{REFERENCES}

[1] R. S. Vedam and M. S. Sarma, Power Quality: VAR Compensation in Power Systems, CRC press New York, Dec. 2017.

[2] K. R. Padiyar, FACTS Controllers in Power Transmission and Distribution, New Age International publishers, New Delhi, 2007.

[3] B. Singh, A. Chandra, and K. Al-Haddad, Power Quality: Problems and Mitigation Techniques, John Wiley and Sons, 2014.

[4] IEEE Recommended Practices and Requirement for Harmonic Control on Electric Power System, IEEE Standard 519, 1992.

[5] F. M. Mahdianpoor, R. A. Hooshmand, and M. Ataei, "A new approach to multifunctional dynamic voltage restorer implementation for emergency control in distribution systems," IEEE Trans. on Power Delivery, vol. 26, no. 2, pp. 882-890, Apr. 2011.

[6] F. B. Ajaei, S. Afsharnia, A. Kahrobaeian, and S. Farhangi, "A fast and effective control scheme for the dynamic voltage restorers," IEEE Trans. on Power Delivery, vol. 26, no. 4, pp. 2398-2406, Oct. 2011.

[7] P. Roncero-Sanchez, E. Acha, J. E. O. Calderon, V. Feliu, and A. G. Cerrada, "A versatile control scheme for a dynamic voltage restorer for power-quality improvement," IEEE Trans. on Power Delivery, vol. 24, no. 1, pp. 277-284, Jan. 2009.

[8] C. Wessels, F. Gebhardt, and F. W. Fuchs, "Fault ride-through of a DFIG wind turbine using a dynamic voltage restorer during symmetrical and asymmetrical grid faults," IEEE Trans. on Power Electronics, vol. 26, no. 3, pp. 807-815, Mar. 2011.

[9] A. M. Gee, F. Robinson, and W. Yuan, "A superconducting magnetic energy storage-emulator/battery supported dynamic voltage restorer," IEEE Trans. on Energy Conversion, vol. 32, no. 1, pp. 55-64, Mar. 2017.

[10] J. G. Nielsen, M. Newman, H. Nielsen, and F. Blaabjerg, "Control and testing of a dynamic voltage restorer (DVR) at medium voltage level," IEEE Trans. on Power Electronics, vol. 19, no. 3, pp. 806-813, May 2004.

[11] C. Zhan, C. Fitzer, V. K. Ramachandaramurthy, A. Arulampalam, M. Barnes, and N. Jenkins, "Software phase-locked loop applied to dynamic voltage restorer (DVR)," in Proc. IEEE Power Engineering Society Winter Meeting, Columbus, OH, USA, 2001, pp. 1033-1038, vol. 3 .

[12] M. Karimi-Ghartema, Enhanced Phase-Locked Loop Structures for Power and Energy Applications, John Wiley and Sons, New Jersey, Mar. 2014.

[13] S. Eren, M. Karimi-Ghartemani, and A. Bakhshai, "Enhancing the three-phase synchronous reference frame PLL to remove unbalance and harmonic errors," 2009 35th Annual Conference of IEEE 
Industrial Electronics, Porto, 2009, pp. 437-441.

[14] M. Bodson and S. C. Douglas, "Adaptive algorithms for the rejection of sinusoidal disturbances with unknown frequency," Journal of Automatica, vol. 33, no. 12, pp. 2213-2221, Dec. 1997.

[15] D. Yazdani, M. Mojiri, A. Bakhshai, and G. Joos, "A fast and accurate synchronization technique for extraction of symmetrical components," IEEE Trans. on Power Electronics, vol. 24, no. 3, pp. 674-684, Mar. 2009.

[16] G. Yin, L. Guo, and X. Li, "An amplitude adaptive notch filter for grid signal processing," IEEE Trans. on Power Electronics, vol. 28, no. 6, pp. 2638-2641, Jun. 2013.

[17] A. B. Shitole, H. M. Suryawanshi, G. G. Talapur, S. Sathyan, M. S. Ballal, V. B. Borghate, M. R. Ramteke, and M. A. Chaudhari, "Grid interfaced distributed generation system with modified current control loop using adaptive synchronization technique," IEEE Trans. on Industrial Informatics, vol. 13, no. 5, pp. 2634-2644, Oct. 2017.

[18] C. C. Hang and K. K. Sin, "A comparative performance study of PID auto-tuners," IEEE Control Systems Mag., vol. 11, no. 5, pp. 41-47, Aug. 1991.

[19] M. Pluhacek, R. Senkerik, I. Zelinka, and D. Davendra, "Designing PID controllers by means of PSO algorithm enhanced by various chaotic maps," in 2013 8th EUROSIM Congress on Modelling and Simulation, Cardiff, 2013, pp. 19-23.

[20] N. Kassarwani, J. Ohri, and A. Singh, "Design and performance of dynamic voltage restorer using genetic algorithm," International Journal of Electronics, vol. 105, no. 1, pp. 88-103, 2018.

[21] M. Sharawi, H. M. Zawbaa, E. Emary, H. M. Zawbaa, and E. Emary, "Feature selection approach based on whale optimization algorithm," 2017 Ninth International Conference on Advanced Computational Intelligence (ICACI), Doha, 2017, pp. 163-168.

[22] S. Mirjalili and A. Lewis, "The whale optimization algorithm," Advances in Engineering Software, no. 95, pp. 51-67, May 2016.

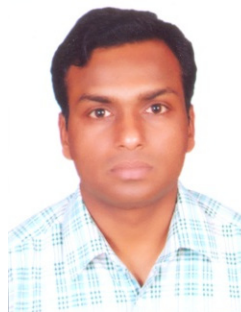

Rakesh Maurya received B. Tech in Electrical Engineering from the Kamla Nehru Institute of Technology Sultanpur, Uttar Pradesh in 1998 and M. Tech and Ph.D. in Electrical Engineering from Indian Institute of Technology Roorkee, India in 2002 and 2014 respectively. Presently, he is serving as faculty member in the department of Electrical Engineering, Sardar Vallabhbhai National Institute of Technology Surat, Gujarat, India. His fields of interest include design of Switching Power Converters, High power factor AC/DC Converters, hybrid output converter, Power quality problems, Advanced Electric drives and applications of Real Time Simulator for the control of power converters.

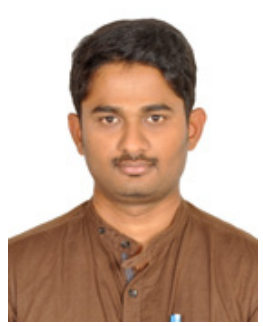

Talada Appala Naidu received his B.Tech. in Electrical and Electronics Engineering from JNTU Kakinada, Andhra Pradesh, India, in 2012 and M. Tech. in Electrical Engineering with specialization in Power Electronics and Electrical Drives from Sardar Vallabhbhai National Institute of Technology, Surat, Gujarat, India in 2016. In 2016, he joined as Junior Research Fellow in Department of Science and Technology (DST) project funded by Science and Engineering Research Board (SERB), Govt. of India in Electrical Engineering Department, Sardar Vallabhbhai National Institute of Technology (SVNIT), Surat-395007, where he is currently pursuing $\mathrm{Ph} . \mathrm{D}$. degree. His research fields of interest includes the applications of power electronics in distribution systems, power quality and active filters.

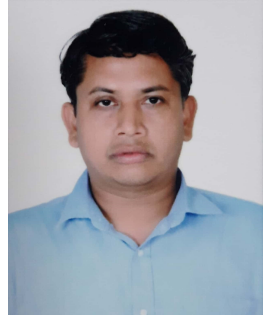

Sabha Raj Arya received Bachelor of Engineering degree in Electrical Engineering from Government Engineering College Jabalpur, in 2002, Master of Technology in Power Electronics from Motilal National Institute of Technology, Allahabad, in 2004 and Ph.D. degree in Electrical Engineering from Indian Institute of Technology (I.I.T) Delhi, New Delhi, India, in 2014. He is joined as Assistant Professor, Department of Electrical Engineering, Sardar Vallabhbhai National Institute of Technology, Surat. His fields of interest include power quality, design of power filters and distributed power generation.

He received Two National Awards namely INAE Young Engineer Award from Indian National Academy of Engineering, POSOCO Power System Award from Power Grid Corporation of India in the year of 2014 for his research work. He is also received Amit Garg Memorial Research Award-2014 from I.I.T Delhi from the high impact publication in a quality journal during the session 2013-2014. He serves as an Associate Editor for the IET (U.K.) Renewable Power Generation. 